\section{AB1346 THE CLINICAL COURSE OF PATIENTS WITH BIOLOGICS-TREATED RHEUMATOID ARTHRITISCOMPLICATED WITH NONTUBERCULOUS MYCOBACTERIAL LUNG INFECTION}

T. Kise, K. Shimada, Y. Miyoshi, N. Yokogawa, S. Sugii. Department of Rheumatic Diseases, Tokyo Metropolitan Tama Medical Center, Fuchushi, Tokyo, Japan

Background: For now, it has been difficult for rheumatoid arthritis (RA) patients with lung nontuberculous mycobacterial infection (LNTMI) to achieve therapeutic goal of RA because of insufficient treatment considering the risk of NTM deterioration by immunosuppressive therapy. Although use of biologics in RA with LNTMI is not recommended based on results of an epidemiological study from USA, ${ }^{12}$ prognosis analysis considering confounding factors, including the species of NTM, remains to be studied. On the other hand, some Japanese case series of RA with LNTMI after biological treatment had shown the acceptable outcomes. ${ }^{3}$

Objectives: This study was performed in order to investigate clinical course of patients with biologics-treated RA complicated with LNTMI.

Methods: This study is descriptive study. All the patients diagnosed with RA and proved the positivity of acid fasting culture were extracted. We retrospectively collected the clinical data between 1 Jan 2011 and 31, Mar 2017 including age, sex, date of RA onset, onset of NTM infection, species of NTM organisms, biologic drugs used, the clinical course, the findings of high resolution computed tomography (HRCT) and the outcome after commencement of biologics, at Tokyo Metropolitan Tama Medical Centre. The diagnosis of LNTMI was made by satisfying both of the two following conditions; ${ }^{1}$ either positivity of bronchoalveolar lavage fluid culture at least once or sputum culture twice or more $a d^{2}$ the compatible findings with LNTMI on HRCT.

Results: During investigation period, 13 LNTMI-RA patients were administered biologics, of which $76.9 \%$ were female. Their mean age at NTM diagnosis was 71 years old. The duration between the RA diagnosis and the occurrence of LNTMI ranged widely from 1 to 40 years. The species of NTM were Mycobacterium. avium (12 cases) and $M$. intracellulare (1 case), which did not include rapid growing species. Twelve cases had treated with glucocorticoid. Of 10 cases who underwent biologics therapy after NTM diagnosis, 6 had continued biologics after diagnosis of LNTMI. All the 4 of the 13 cases who first received biologics after diagnosis of LNTMI were treated with abatacept, which improved their RA activity and did not exacerbate LNTMI. Of the 13, there were no patients requiring home oxygen therapy. During the average observational period after LNTMI of 3.6 years (0.8-10.3 years), 10 of the 13 were alive and 3 died, whose causes of death were not directly associated with LNTMI. When each period upon every biologics was independently calculated, the Kaplan-Meier survival curve illustrated the tendency of survival difference of between LNTMI-RA cases treated with non-TNF inhibitors and those with TNF inhibitors (figure 1).

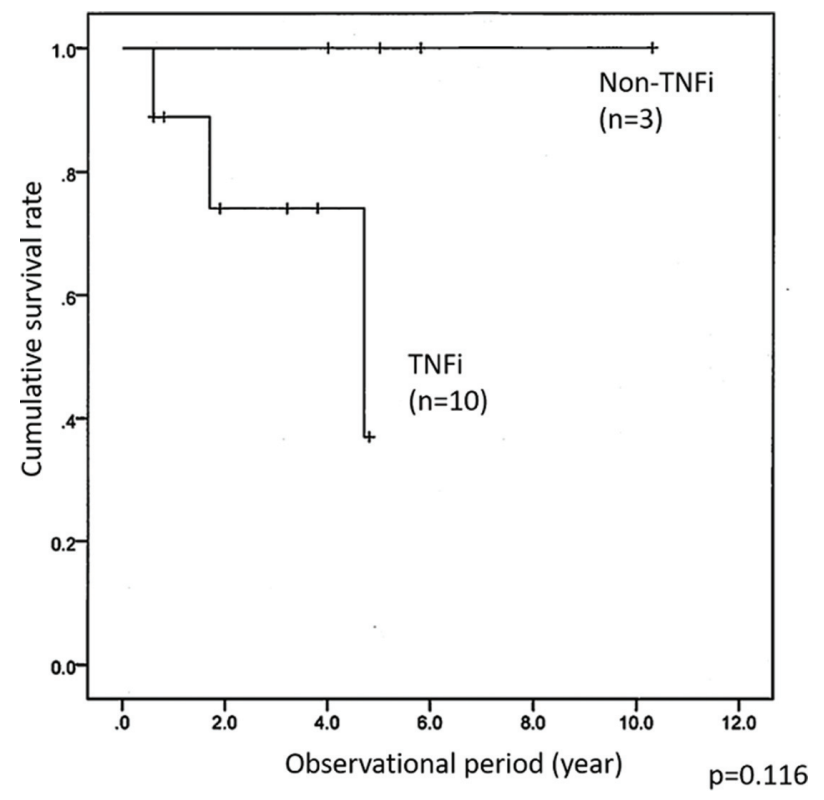

Abstract AB1346 - Figure 1

Conclusions: Even when patients with RA have LNTMI of not rapid growing species, RA may be safely and sufficiently treated by abatacept with careful monitoring of the respiratory condition, which may improve their joint prognosis.
REFERENCES:

[1] Winthrop KL, et al. Emerg Infect Dis. 2009;15(10):1556-61.

[2] Winthrop KL, et al. Ann Rheum Dis. 2013;72(1):37-42.

[3] Mori S, et al. Mod Rheumatol. 2012;22(5):727-37.

Disclosure of Interest: None declared

DOI: 10.1136/annrheumdis-2018-eular.2360

\section{AB1347 ELEVATED NESFATIN-1 LEVELS IN PATIENTS WITH RHEUMATOID ARTHRITIS}

T.Z. Kvlividze' ${ }^{1}$, B.V. Zavodovsky ${ }^{2}$, Y.R. Akhverdyan², L.E. Sivordova ${ }^{2}$, Y. V. Polyakova ${ }^{2}$, D.P. Lavrova ${ }^{1}$, A.T. Yakovlev ${ }^{1} .{ }^{1}$ Volgograd State Medical University, Volgograd, Russian Federation; ${ }^{2}$ Federal State Budgetary Institution "Research Institute of Clinical and Experimental Rheumatology named after A.B. Zborovsky"., Volgograd, Russian Federation

Background: Recent studies indicate that adipokines affect tissues and cells involved in rheumatoid arthritis (RA), including synovium, cartilage, bone, and immune cells. ${ }^{1,2,3}$ Nesfatin-1, a member of the adipokine family, was identified in 2006 as a potent anorexigenic peptide involved in the regulation of homeostatic feeding. Nesfatin-1 concentrations in serum and synovial fluid were closely correlated with disease occurrence and severity of knee osteoarthritis. ${ }^{4}$ We did not found any data about Nesfatin-1 levels in sera of rheumatoid arthritis (RA) patients.

Objectives: To investigate the serum nesfatin- 1 level in RA patients.

Methods: At baseline we measured Nesfatin-1 level in sera of 110 RA patients

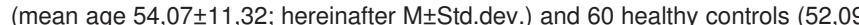
$\pm 14,12$ ). The diagnosis of RA was set according to the ACR/. ${ }^{\text {EULAR Classification Crite- }}$ ria for RA (2010) Serum C-reactive protein (CRP) and erythrocyte sedimentation rate (ESR) were measured to assess inflammation severity. Nesfatin-1 in serum was determined by enzyme-linked immunosorbent assay (RaiBiotech, cat№ EIA NESF).

Results: We revealed that nesfatin- 1 levels in RA patients was equal 50,49 $\pm 34,05 \mathrm{ng} / \mathrm{ml}$ and was higher than of healthy controls $-31,61 \pm 3,17 \mathrm{ng} / \mathrm{ml}$. We divided 120 RA patients into 2 subgroups -1 st $(n=44)$ with normal nesfatin- 1 concentration in sera, and 2nd ( $n=66)$ - with increased nesfatin-1 level. We noted that 2nd group's patients had higher DAS28 activity index, functional joints disability, higher levels CRP and ESR.

Conclusions: The present study shows that RA patients have increased serum Nesfatin-1 levels which strongly correlated with systemic inflammation and func tional impairment in RA. These data sustained the pathogenic role of Nesfatin-1 in RA progression.

\section{REFERENCES}

[1] Sivordova U, Zavodovsky B, Polyakova U, et all. Adiponectin as a usefu marker for diagnosis of osteoporosis in rheumatoid arthritis patients. Osteoporosis Int. 2016;27(S.1):135

[2] Seewordova L, Polyakova U, Zavodovsky B, et al. Adiponectin determination in rheumatoid arthritis patients complicated by osteoporosis. EULAR 2016;75(S.2):970-971.

[3] Polyakova Y, Sivordova L, Akhverdyan Y, Kravtcov V, Zavodovsky B. New biomarker for diagnosis of osteoporosis in rheumatoid arthritis patients. Annals of the Rheumatic Diseases, 2017 -76, 2- 699.

[4] Zhang $Y$, Shui X, Lian X, Wang G. Serum and synovial fluid nesfatin-1 concentration is associated with radiographic severity of knee osteoarthritis. Med Sci Monit. 2015;21:1078-1082.

Disclosure of Interest: None declared

DOI: 10.1136/annrheumdis-2018-eular.4459

\section{AB1348 PREVALENCE, GENDER-PREDOMINANCE AND CLINICAL PRESENTATION OF BEHCET'S DISEASE IN EGYPT: PRELIMINARY FINDINGS FROM A MULTICENTER NATIONWIDE STUDY}

, T. A. Gheita ${ }^{1, *}$, E.M. Abd El-Latif ${ }^{2}$, I.I. El-Gazzar ${ }^{1}$, N. Samy ${ }^{3}$, N.H. Hammam ${ }^{4}$, A. R. E-Najjar ${ }^{5}$, M.N. Salem ${ }^{6}$, D.F. El-Essawi ${ }^{7}$, H.M. Fathi ${ }^{8}$, R.R. El-Shereef ${ }^{9}$, M.I. Abd Elazeem $^{10}$, N.M. Khaliil ${ }^{11}$, S.I. Nasef ${ }^{12}$, S.E. Ibrahim ${ }^{13}$, H.M. Khaliil ${ }^{14}$, on behalf of Egyptian College of Rheumatology - Behçet's Disease Study Group (ECR-BDSG).

${ }^{1}$ Rheumatology, Faculty of Medicine, Cairo University, Cairo, ${ }^{2}$ Ophthalmology Faculty of Medicine, Alexandria University, Alexandria, ${ }^{3}$ Internal Medicine, Rheu matology Unit, Faculty of Medicine, Ain Shams University, Cairo, ${ }^{4}$ Rheumatology, Faculty of Medicine, Assuit University, Assuit, ${ }^{5}$ Rheumatology, Faculty of Medicine, Zagazig University, Zagazig, ${ }^{6}$ Internal Medicine, Rheumatology Unit, Faculty 